
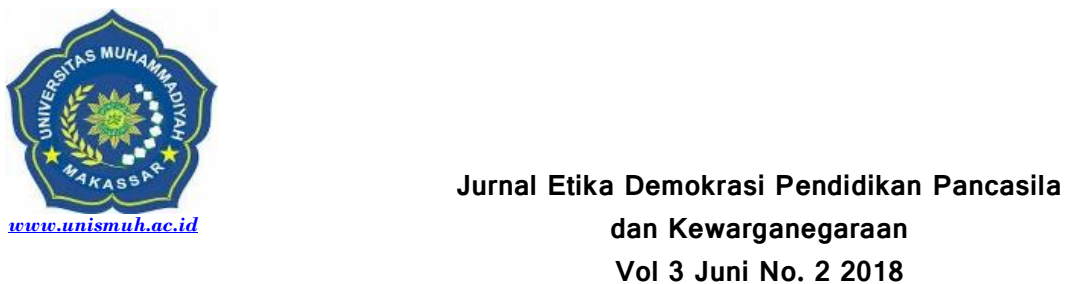

\title{
Pemahaman tentang Nilai-Nilai Pancasila di Masyarakat Pedesaan Desa Gunung Perak Kecamatan Perak Kecamatan Sinjai Barat Kabupaten Sinjai
}

\author{
Auliah Andika Rukman \\ Pendidikan Pancasila dan Kewarganegaraan FKIP Universitas Muhammadiyah Makassar \\ auliahandikarukman@unismuh.ac.id
}

\begin{abstract}
The main problem in this study is how to understand the Pancasila Values in the community in Gunung Perak Village, West Sinjai District. This research aims to find out how the understanding of Pancasila Values in the community in Gunung Perak Village, Sinjai Barat District.The type of this research is that qualitative research with descriptive analysis method is used to examine the natural subject conditions and the research data is more concerned with interpretation of data found in the field. The results showed that the understanding of Pancasila values was still lacking, which was seen from the results of the study, namely 6 people who did not understand and 4 people who understood this occurred due to a lack of education levels in the past. The lack of public awareness about the values of the Pancasila needs to be carried out so that in the life of the community the value of the Pancasila is not merely a reading and noble values but increases people's understanding. Based on the results of the above research, it can be concluded that the understanding of Pancasila values in rural communities (Gunung Perak Village, West Sinjai District, Sinjai District) through qualitative research with descriptive methods of understanding has not been fully distributed.
\end{abstract}

Keywords : Understanding, Pancasila Values, Society.

\begin{abstract}
Abstrak. Masalah utama dalam penelitian ini yaitu bagaimana pemahaman mengenai Nilai-Nilai Pancasila pada masyarakat di Desa Gunung Perak Kecamatan Sinjai Barat. Penelitian ini bertujuan untuk mengetahui bagaimana pemahaman mengenai Nilai-Nilai Pancasila pada masyarakat di Desa Gunung perak Kecamatan Sinjai Barat. Jenis penelitian ini adalah penelitian kualitatif dengan metode analisis deskriptif digunakan untuk meneliti pada kondisi subjek yang alamiah serta data hasil penelitian lebih berkenaan dengan interprestasi terhadap data yang ditemukan di lapangan. Hasil penelitian menunjukkan bahwa pemahaman nilai-nilai Pancasila masih kurang, dimana dilihat dari hasil penelitian yaitu 6 orang yang kurang memahami dan 4 orang yang memahami hal tersebut terjadi karena kurangnya tingkat pendidikan pada zaman dahulu. Kurangnya kesadaran masyarakat tentang nilai-nilai pancasila perlu dilaksanakan sosialisasi agar dalam kehidupan masyarakat nilai pancasila ini bukan sekedar bacaan dan nilainilai luhur semata tetapi meningkatkan pemahaman masyarakat. Berdasarkan hasi penelitian di atas, dapat disimpulkan bahwa pemahaman tentang nilai-nilai pancasila di masyarakat pedesaan (Desa Gunung Perak Kecamatan Sinjai Barat Kabupaten Sinjai) melalui penelitian kualitatif dengan metode deskriprif pemahaman belum sepenuhnya merata.
\end{abstract}

Kata kunci: Pemahaman, Nilai-Nilai Pancasila, Masyarakat 


\section{PENDAHULUAN}

Terbentuknya nilai-nilai pancasila dalam sikap suatu masyarakat yang baik merupakan salah satu keberhasilan dalam mencapai tujuan nilai-nilai pancasila, hal ini didukung dengan adanya pemahaman nilai-nilai pancasila di desa gunung perak yang masih kurang memahami tentang nilainilai pancasila dalam masyarakat, dimana masyarakat hanya dapat mengaplikasikan nilai budaya sipaktau, sipakainge dan sipakalebbi yang menjadikan masyarakat lebih cenderung dengan kultutur budaya adat yang di tinggalkan oleh leluhur-leluhur ketimbang nilai-nilai pancasila. Dengan adanya dinamika masyarakat pada umumnya yang ada di Desa Gunung Perak menjadikan alasan peneliti lebih cenderung tentang pemahaman nilai nilai pancasila di masyarakat pedesan terkhusus di Desa Gunung Perak.

Nilai-nilai pancasila merupakan nilai yang berlaku dalam suatu lingkungan sosial dan mengatur tingkah laku seseorang, yang artinya nilai-nilai pancasila menjadi tolak ukur yang dipakai oleh masyarakat untuk menentukan baik buruknya tindakan masyarakat sebagai manusia. Disini manusia berhak mengaplikasikan nilai-nilai pancasila kepada masyarakat lain berdasarkan tingkah laku yang di landasi dengan nilai-nilai pancasila yang ada dan undang-undang dasar 1945.

Pembinaan nilai pancasila bagi masyarakat sangat penting untuk menjunjung tinggi nilai pemerintahan dalam menerapkan pemahaman masyarakat dengan nilai-nilai pancasila. Pada hakekatnya pembinaan nilai pancasila masyarakat merupakan sebuah aspek yang sangat sentral dalam kehidupan sosial. Keberadaan pembinaan nilai pancasila dimulai sejak dini, sehingga dalam hal ini sudah menjadi suatu keharusan yang harus dilakukan untuk perbaikan sikap maupun nilai pancasila pada masyarakat. Pembinaan nilai-nilai pancasila tidak bisa hanya dengan kegiatan proses sosialisai saja dalam masyarakat tapi perlu juga mengaplikasikan dalam masyarakat, melainkan pembinaan nilai-nilai pancasila disertai oleh lembaga pemerintah setempat dalam upaya mengembangkan karakter sosialisasi masyarakat.
Pancasila sangat penting dalam kehidupan berbangsa dan bernegara, serta harus tertanam dalam diri setiap warga negara Indonesia dan diamalkan dalam kehidupan sehari-hari berbangsa dan bernegara. Berbagai upaya sudah pernah dilakukan oleh para pemimpin bangsa agar Pancasila dapat tertanam dalam diri setiap warga negara Indonesia seperti dengan adanya Pendidikan Moral Pancasila (PMP) dan Ketetapan Majelis Permusyawaratan Rakyat Nomor II/MPR/1978 tentang Ekaprasetia Pancakarsa yang menjabarkan kelima asas dalam Pancasila menjadi 36 butir pengamalan sebagai pedoman praktis bagi pelaksanaan Pancasila. Pada tahun 2003 Tap MPR Nomor II/MPR/1978 dicabut dengan Tap MPR Nomor I/MPR/2003 dengan 45 butir pengamalan Pancasila, namun dalam kenyataannya tidak dipublikasikan kajian mengenai butir-butir Pancasila benar-benar diamalkan dalam keseharian masyarakat di Indonesia atau tidak (Kaelan, 2010: 26).

Pancasila merupakan kekayaan bangsa Indonesia yang tidak ternilai harganya, merupakan manifestasi nilai-nilai luhur yang digali Bung Karno dari akar budaya bangsa yang mencakup seluruh kebutuhan dan hak-hak dasar manusia secara universal, sehingga dapat dijadikan landasan dan falsafah hidup bangsa Indonesia yang majemuk baik dari segi agama, etnis, ras, bahasa, golongan dan kepentingan. Sudah selayaknya, bangsa Indonesia mengembangkan dan mengamalkan nilai-nilai Pancasila sebagai dasar kehidupan berbangsa dan bernegara untuk mewujudkan citacita bangsa. Melihat kenyataan bahwa saat ini banyak masyarakat Indonesia yang mulai melupakan ajaran Pancasila, maka peneliti mencoba untuk menggali atau mendeskripsikan "seberapa besar pemahaman mengenai nilai-nilai Pancasila pada masyarakat beserta faktor yang mempengaruhinya melalui study eksplorasi di Desa Gunung Perak Kecamatan Sinjai Barat Kabupaten Sinjai.

Pemahaman bukan kegiatan berpikir semata, melainkan pemindahan letak dari dalam berdiri disituasi atau dunia orang lain. Mengalami kembali situasi yang dijumpai pribadi lain 
didalam erlebnis (sumber pengetahuan tentang hidup, kegiatan melakukan pengalaman pikiran), pengalaman yang terhayati. Pemahaman merupakan suatu kegiatan berpikir secara diamdiam, menemukan dirinya dalam orang lain. Pemahaman mengenai Pancasila pada masyarakat dipengaruhi banyak hal, misalnya menurunnya nilai-nilai Pancasila dalam masyarakat karena kurangnya tingkat pendidikan sebagai pandangan hidup merupakan faktor-faktor yang menyebabkan masyarakat meninggalkan nilai-nilai luhur Pancasila (Poesprodjo, 1987: 52-53).

Masalah yang dapat dikemukakan antara lain bagaimana pemahaman masyarakat mengenai nilai-nilai Pancasila serta faktor yang mempengaruhinya. Masyarakat adalah kumpulan individu yang terdiri dari berbagai kepribadian yang berbeda-beda, jadi pahaman masyarakat mengenai Pancasila juga berbeda-beda. Dalam hal ini pemerintah memiliki peran yang sangat penting untuk membantu masyarakat dalam memahami Pancasila.

\section{METODE PENELITIAN}

Jenis penelitian yang digunakan dalam penelitian ini adalah penelitian deskriptif kualitatif. Yang terdapat Sumber data dalam penelitian ini yaitu data primer dan data sekunder. data primer adalah data yang diperoleh langsung dari sumbernya. Sumber data primer yang digunakan dalam penelitian ini adalah masyarakat desa gunung perak kecamatan sinjai barat kabupaten sinjai dan data sekunder dalam penelitian ini adalah data yang diperoleh bukan secara langsung dari sumbernya. Dalam penelitian ini sumber data sekunder yang dipakai adalah sumber tertulis seperti data-data kantor desa. Populasi dalam penelitian ini adalah seluruh masayarakat di Desa Gunung Perak Kecamatan Sinjai Barat Kabupaten Sinjai yang berjumlah 3125 penduduk. Informan penelitian ini peneliti mengambil 10 orang sampel, 5 orang laki-laki dan 5 orang perempuan. Data ini dikumpulkan dengan menggunakan :

1. Observasi yaitu mengadakan pengamatan langsung dilapangan untuk mengetahui dan mengamati keadaan kehidupan di lokasi. Penelitian ini dimaksudkan untuk mengetahui objektivitas dari kenyataan yang akan ada tentang keadaan kondisi objek yang akan diteliti.

2. Wawancara mendalam yaitu mengumpulkan sejumlah data dan informasi secara mendalam dari informan dengan menggunakan pedoman wawancara atau peneliti melakukan kontak langsung dengan subjek peneliti secara mendalam, utuh dan terperinci.

3. Dokumentasi yaitu suatu cara yang dilakukan untuk menyediakan dokumen dengan menggunakan bukti yang akurat sesuai dengan kejadian yang ada di lapangan.

\section{PEMBAHASAN}

Pemahaman Nilai-Nilai Pancasila pada Masyarakat di Desa Gunung Perak Kecamatan Sinjai Barat Kabupaten Sinjai

Pemahaman Nilai-nilai Pancasila seperti nilai ketuhanan, nilai kemanusiaan, nilai persatuan, nilai kerakyatan, dan nilai keadilan diterapkan dalam kehidupan masyarakat Desa Gunung Perak Kecamatan sinjai barat Kabupaten Sinjai. Hal ini dapat terlihat dalam melaksanakan pembangunan desa selalu berdasarkan nilai-nilai Pancasila, contohnya dalam pembangunan masjid, jalan desa, menggunakan nilai-nilai Pancasila seperti gotong royong, toleransi, musyawarah dan menjunjung tinggi nilai keadilan bahwa besarnya penerapan nilai-nilai Pancasila tersebut adalah 91,5\%, yang interprestasinya adalah sempurna artinya seluruh nilai-nilai diterapkan dan menolak nilai yang bertentangan dengan nilai-nilai Pancasila. Ada beberapa penerapan nilai-nilai Pancasila antara lain:

Pemahaman masyarakat terhadap nilai ketuhanan Meskipun masyarakat Desa Gunung Perak beragama Islam namun pemahaman mereka tentang Tuhan sama dengan konsep Tuhan dalam Pancasila. Mereka menghargai kepercayaan warganegara lain. Setiap agama yang diakui di Indonesia meyakini bahwa Tuhan itu hanya satu. Prinsip Ketuhanan Yang Maha Esa ini meminta masyarakat Indonesia mengakui keberadaan 
Tuhan, dengan kata lain prinsip percaya pada Tuhan YME mencerminkan kepercayaan rakyat Indonesia terhadap kehidupan setelah hidup di dunia atau alam baka. Ini mempengaruhi mereka kearah kepatuhan terhadap nilai-nilai yang dihormati untuk membuka jalan bagi mereka agar mendapatkan kehidupan yang lebih baik di alam baka. Prinsip ini ditekankan dalam pasal 29 ayat 1 UUD 1945 yang berbunyi "Negara berdasarkan Ketuhanan Yang Maha Esa". Tujuan utama dari nilai ini adalah untuk menciptakan keselarasan antar rakyat yang mempunyai keyakinan agama yang berbeda, tetapi yang mengakui keesaan, kekuasaan dan keadilan Tuhan. Ciri-ciri manusia seperti di atas adalah pencerahan, toleransi, berpandangan luas, hormat, kerjasama, harmonis, keadilan, kebenaran, kewajaran, kenetralan dan kebijaksanaan Sumantri (2008, 99-100).

\section{Pemahaman masyarakat terhadap nilai kemanusian}

Masyarakat Desa Gunung Perak sekarang bukan lagi seperti masyarakat pada awal. Karena masyarakat Desa Gunung Perak sekarang lebih mengedepankan nilai kemanusia ketimbang nilai individualis. Prinsip Kemanusiaan Yang Adil dan Beradab berharap manusia untuk diperlakukan secara bermartabat sesuai dengan makhluk ciptaan Tuhan. Sehingga, orang Indonesia tidak memaafkan tekanan terhadap orang baik yang berasal dari dalam maupun dari luar negeri secara fisik maupun spiritual. Tujuan utama dari keyakinan ini adalah keselarasan antara nasional dan internasional. Jika dalam pandangan Tuhan semua manusia sama. Kalau begitu pasti terdapat persaudaraan diantara mereka. Ciri-ciri manusia seperti di atas adalah kelurusan moral, tidak berpihak terhadap politisi, kesadaran global, penghormatan terhadap rakyat lain, komitmen untuk kebenaran dan keadilan, bermartabat dan kemanusiaan (Sumantri, 2008, 101).

\section{Pemahaman masyarakat terhadap nilai persatuan}

Prinsip Persatuan Indonesia mempromosikan tentang nasionalisme, cinta tanah air dan kebutuhan untuk selalu memelihara kesatuan negara dan mempromosikan integrasi nasional. Nasionalisme Pancasila sering disebut untuk mengesampingkan perasaan superioritas berdasarkan pada etnik (kedaerahan), keturunan atau warna kulit orang Indonesia. Simbol negara Indonesia menekankan pada prinsip "Bhineka Tunggal Ika" yang berarti Kesatuan dalam Keberagaman (berbeda beda tetapi satu). Dalam kehidupan sehari-hari perbedaan yang bermacammacam tidak berpengaruh terhadap kesatuan dan integritas nasional. Tujuan utama dari keyakinan ini adalah menjaga keserasian nasional dan dunia berdasarkan pada kemerdekaan, keadilan sosial dan perdamaian dunia. Rakyat Indonesia menghargai makna dari penerapan prinsip dasar atas persatuan dalam keanekaragaman, dan meyakini bahwa kepentingan dan keamanan nasional serta negara harus diletakkan di atas kepentingan atau keamanan individu atau kelompok. Seperti nasionalis yang melihat kekuatan dalam keanekaragaman dan percaya dalam kesatuan untuk keuntungan untuk semua dan juga diharapkan untuk cinta tanah air, saling menolong, pengorbanan diri, keberanian, perdamaian dan tanggungjawab (Sumantri, 2008, 102).

\section{Pemahaman masyarakat terhadap nilai kerakyatan}

Prinsip Kerakyatan yang Dipimpin oleh Hikmat Kebijaksanaan dalam Permusyawaratan/ Perwakilan menekankan bahwa demokrasi Pancasila yang terinspirasi dan menyatu dengan prinsip lain Pancasila, berarti bahwa penggunaan hak demokrasi harus selalu berdampingan dengan nilai kemanusiaan, memelihara dan menguatkan kesatuan nasional dan berusaha untuk mewujudkan keadilan sosial. Tujuan utama dari keyakinan ini untuk mendirikan, menjaga dan meningkatkan kesepakatan demokrasi untuk pembangunan bangsa dan negara. Rakyat Indonesia percaya bahwa pernyataan berikut ini benar "bahwasanya manusia itu berdaulat", dan mereka mewakili kedaulatan mereka pada Dewan Perwakilan Rakyat yang mereka pilih. Setiap rakyat diharapkan untuk memiliki kepercayaan di masyarakatnya dan percaya pada kesederajatan objektivitas dan kejujuran Sumantri $(2008,103)$.

Pemahaman masyarakat terhadap nialai keadilan 
Keadilan berasal dari kata adil. Adil artinya sama rata, sama berat, tidak berat sebelah; tidak memihak. Adil juga berarti tidak memandang suku, agama, ras, dan antar golongan. Harus bersikap objektif bukan subjektif kepada masyarakat. Masyarakat Desa Arabika merupakan minoritas di Kabupaten Sinjai. Mereka juga sebagai warganegara yang berhak mendapatkan perlakuan yang sama dengan masyarakat lain. Ketika masyarakat dapat diperlakukan adil otomatis akan tercapainya tujuan negara, yaitu kemakmuran. Prinsip Keadilan Sosial Bagi Seluruh Rakyat Indonesia bertujuan pada pembagian kesejahteraan yang adil diantara manusia, tidak dengan cara statis tapi dengan cara dinamis dan progresif. Ini berarti semua sumber daya alam yang dimiliki negara dan potensi manusianya seharusnya digunakan untuk membawa kebahagiaan terbesar yang mungkin untuk seluruh rakyat. Keadilan Sosial mengandung makna perlindungan untuk yang lemah tetapi yang lemah harus bekerja sesuai dengan kemampuan mereka. Perlindungan diberikan untuk mencegah keberpihakan kepada yang kuat dan untuk meyakinkan akan beradaan hukum. Tujuan utama dari prinsip ini adalah keselaran sosial dan keberadaan yang diterima baik. Sebagai individu rakyat Indonesia percaya bahwa keadilan sosial dimulai dengan penghargaan mereka pada kerja keras untuk keadilan sosial bagi yang lain. Mereka juga percaya bahwa keadilan sosial didirikan pada norma yang sama yang ada pada karakter hubungan keluarga. Setiap rakyat seharusnya bekerja untuk kemuliaan sosial dan bekerja untuk mengakhiri eksploitasi.

\section{Faktor yang mempengaruhi pemahaman} mengenai Nilai-Nilai Pancasila di masyarakat Desa Gunung Perak

Pendidikan formal semestinya mampu memberikan porsi yang istimewa terhadap mata pelajaran yang menyangkut pemahaman nilai-nilai Pancasila sehingga diharapkan setiap generasi dapat mengerti akan cita luhur yang terkandung dalam Pancasila.

Kemudian, situasi dan lingkungan kehidupan bangsa yang telah berubah juga turut mempengaruhi kurangnya pemahaman akan nilai- nilai Pancasila. Situasi dan lingkungan kehidupan bangsa pada tahun 1945, telah mengalami perubahan yang amat nyata pada saat ini, dan akan terus berubah pada masa yang akan datang. Beberapa perubahan yang kita alami antara lain terjadinya proses globalisasi dalam segala aspeknya, lonjakan pemanfaatan teknologi informasi oleh masyarakat, di mana informasi menjadi kekuatan yang amat berpengaruh dalam berbagai aspek kehidupan, tapi juga yang rentan terhadap manipulasi informasi dengan segala dampaknya. Perubahan tersebut telah mendorong terjadinya pergeseran nilai yang dialami bangsa Indonesia, sebagaimana terlihat dalam pola hidup masyarakat pada umumnya, termasuk dalam corak perilaku masyarakat yang terjadi saat ini.

Reaktualisasi Pancasila diperlukan untuk memperkuat paham kebangsaan dan nilai-nilai luhur Pancasila. Sebagai sebuah tata nilai luhur, Pancasila perludiaktualisasikan dalam tataran praksis yang lebih 'membumi' sehingga mudah diimplementasikan dalam berbagai bidang kehidupan, termasuk dikalangan masyarakat. Karena dalam masyarakat generasi muda adalah generasi penerus bangsa yang diharapkan bisa membawa bangsa ini lebih baik di masa yang akan datang tentunya dengan cara pandang yang berwawasan kebangsaan disertai dengan pemahaman nilai-nilai Pancasila.

\section{KESIMPULAN}

Berdasarkan hasil penelitian, analisa, dan pembahasan atas data yang berhasil di himpun tentang pemahaman Nilai-Nilai Pancasila di Masyarakat pedesaan khususnya di Desa Gunung Perak Kecamatan Sinjai Barat dapat di tarik kesimpulan sebagai berikut:

1. Pemahaman masyarakat tentang nilai-nilai pancasila masih kurang, dimana dilihat dari hasil penelitian yaitu 6 orang yang kurang memahami dan 4 orang yang memahami. Hal tersebut terjadi karena rendahnya tingkat pendidikan pada zaman dahulu.

2. Faktor yang mempengaruhi pemahaman NilaiNilai Pancasila di masyarakat Desa Gunung Perak yaitu kurangnya kesadaran ingin 
mengetahui nilai-nilai pancasila karena masyarakat tidak tahu tentang pentingnya nilainilai pancasila untuk diaplikasikan dalam kehidupan mereka, sehingga masyarakat kurang tertarik untuk mengetahui nilai-nilai pancasila. Kurangnya sosialiasasi dari pemerintah, pemerintah kurang memberikan pemahaman tentang nilai-nilai pancasila ke masyarakat lewat sosialisasi. Kurangnya pembelajaran Pendidikan Pancasila dan Kewarganegaraan, dari jenjang pendidikan dasar hingga jenjang pendidikan tinggi sepertinya tidak terlalu diutamakan dan kurang mendapat perhatian baik dari kalangan pelajar maupun pengajar sehingga tidak jarang para generasi muda yang mengabaikan dan tidak memahami akan makna yang terkandung di dalam pancasila itu sendiri.

\section{DAFTAR PUSTAKA}

[1] Aman, Sofyan, dkk. (1982). Pedoman Didaktik Metodik Pendidikan Moral Pancasila untuk para Guru SD, SLTP dan SLTA. Jakarta: PN Balai Pustaka. Anonym.

[2] Anas, Sudijono. (2009). Pengantar Statistik Pendidikan. Jakarta: Rajagrafindo.

[3] Arikunto .(2013). Prosedur Penelitian Suatu Pendekatan Praktik. Jakarta: PT.Rineka Cipta.

[4] Damanhuri DKK, (2016). Implementasi Nilai-Nilai Pancasila Sebagal Upaya pembangunan Karakter Bangsa.

[5] Dardji Darmodihardjo, (1994) Pendidikan Pancasila di Perguruan Tinggi,Penerbit Laboratorium Pancasila IKIP Malang.

[6] Dardji Darmodihardjo,(1988), Santiaji Pancasila, Penerbit Usaha Nasional Surabaya Indonesia.

[7] Darmodiharjo. (1991). Moral Dan Etika. Jakarta: PT Gramedia Pustaka Utama.

[8] Dikdik Baehaqi Arif. (2011). Pembudayaan NilaiNilai Pancasila pada Warga Negara Muda Melalui Pendidikan Kewarganegaraan. Makalah disampaikan dalam Konggresw Pancasila III di Universitas Airlangga Surabaya.

[9] Dipoyudo, Kirdi. (1985). Keadialan Sosial: Seri Penghayatan dan Pengamalan Pancasila I.Jakarta Rajawali.

[10] Hanif Nurcholis, (2011). Pertumbuhan dan penyelenggaraan pemerintah desa. Jakarta: Penerbit ERLANGGA

[11] Indonesia. Undang-Undang (1945) Setelah Amandemen Tentang Agama

[12] Indonesia. Undang-Undang (1945) Setelah Amandemen Tentang Hak Asasi Manusia
[13] Indonesia. Undang-Undang 1945 Tentang Bentuk dan Kedaulatan

[14] Indonesia. Undang-Undang (1945) Tentang Pertahanan dan Keamanan Negara

[15] Indonesia. Undang-Undang (1945) Tentang Warga Negara dan Penduduk

[16] Indonesia. Undang-Undang Nomor 6 Tahun (2014) Tentang Desa

[17] Kaelan, (2002), Filsafat Bahasa: Masalah dan Perkembangannya. Yogyakarta: Paradigma

[18] Kaelan. (1996). Filsafat Pancasila. Yogyakarta: Paradigma.

[19] Kaelan. (2010). Pendidikan Pancasila. Yogyakarta: Paradigma.

[20] Kaelan. (2007). Pendidikan Pancasila. Yogyakarta: Paradigma.

[1] Kaelan. (2009). Filsafat Pancasila Pandangan Hidup Bangsa Indonesia. Yogyakarta: Paradigma.

[21] Narmoatmojo, W. (2014). Seri Pendidikan Politik buku 1 Pancasila dan UUD 1945. Yogyakarta: Ombak.

[22] Poesprodjo. (1987). Beberapa catatan pendekatan filsafatinya. Bandung: Remaja Karya

[23] Purwito Adi, (2016). Pembudayaan Nilai-Nilai Pancasila Bagi Masyarakat Sebagai Modal Pertahanan Nasional NKRI.

[24] Rofei, (2011). Pengertian Pemahaman Menurut Para Ahli. http://akmapala09.blogspot.co.id/2011/10/pengert ian-pemahaman-menurut-para ahli.html, diakses Kamis, 20 Oktober 2018

[25] Rukiyati, Purwastuti, L.A., Dwikurniani,D., et al. (2013). Pendidikan Pancasila. Yogyakarta: UNY Press.

[26] Rumiati. (2007). Pengembangan Pendidikan Kewarganegaraan SD. Surakarta: Dendidikan Pendidikan Nasional 2007.

[27] Sudaryono. (2012). Dasar-dasar Evaluasi Pembelajaran. Yogyakarta: Graha Ilmu.

[28] Sugiyono. (2013). Metode Penelitian Kuantitatif, Kualitatif dan R\&D. Bandung: Alfabeta. CV.

[29] Sumantri. (2008). Implementasi KTSP dalam Inovasi Pendidikan dan Pembelajaran bagi Pembangunan Karakter Bangsa (Suplemen Dasar Konsep Pendidikan Nilai Moral), Makalah disampaikan pada komunitas pendidik dan stakeholder pendidikan ntuk bahan seminar pendidikan karakter bangsa, Maret 2008.

[30] Winarno, Budi, (2010). Melawan Gurita Neoliberalisme, Erlangga, Jakarta. 